\title{
Caminos de la resistencia maya
}

\author{
Federico Navarrete Linares
}

LAURA CASO BARRERA, 2002

\section{Caminos en la selva. Migración, comercio} y resistencia. Mayas yucatecos e itzaes, \section{siglos XVII-XIX}

FCE-El Colegio de México, México.
$\mathrm{E}$ n Caminos en la selva... Laura Caso presenta una minuciosa reconstrucción histórica de la resistencia maya al dominio colonial y del constante y eterno vagar de este pueblo indígena por las selvas de Yucatán y el Petén. A la luz de este rico panorama podemos comprender cómo los mayas coloniales se movían por la selva con la rapidez y la habilidad con que los marinos navegan por el mar y cómo escapaban al dominio español en su inmensidad de hojas y árboles. La autora nos muestra que para ellos este hábitat era una casa familiar y acogedora, pues conocían sus intrincados caminos, sus incontables recursos, su opulencia y su variedad sin límite. Para los españoles, en cambio, la "montaña”, como la llamaban, no dejó nunca de ser un ámbito desconocido y hostil, un espacio temible y a la vez promisorio cuyas hipotéticas riquezas mismo en que era dominado. La selva, ese desierto exuberante, es pues uno de los personajes principales de la historia que nos cuenta Laura Caso. se evaporaban siempre en el momento

FEDERICO NAVARRETE LINARES: UNAM.

Desacatos, núm. 13, invierno 2003, pp. 188-191.
Otros actores centrales de este relato, que abarca los largos siglos entre la conquista y el fin de la dominación colonial, son, naturalmente, los muy diferentes tipos de españoles que insistían en poblar una provincia que consideraban lamentablemente pobre, sobre todo en comparación con las regiones mineras de México y Perú. Éstos eran los encomenderos y las autoridades, los colonos y los soldados, los clérigos regulares y seculares que se disputaban acremente la única fuente de riqueza de Yucatán: el trabajo de los indígenas mayas.

A partir de un cuidadoso y ejemplar trabajo de archivo, Laura Caso reconstruye sus métodos para extraer de la población nativa la mayor cantidad de esfuerzo y riquezas, sus eternas trifulcas por tener un mayor acceso a éstas, sus prejuicios inamovibles respecto a una población que consideraban holgazana y torpe aunque vivieran a expensas de sus esfuerzos y sus conocimientos, de sus habilidades y su paciencia. La reconstrucción que hace la autora del régimen colonial 
español resulta particularmente interesante porque muestra su pluralidad y variedad, porque logra que los documentos del Archivo General de Indias y del Archivo General de Centro América revelen las voces individuales de cabos y gobernadores, curas y soldados en su eterna disputa por el trabajo indígena.

Pero los protagonistas de Caminos en la selva... son, sin duda, las mujeres y hombres mayas que se enfrentaron a esta colonización depredadora por los medios más diversos, desde la colaboración con los colonizadores, como en el caso de algunos linajes nobles del norte de Yucatán como los Xiu, hasta la rebelión abierta contra el dominio español. Sin embargo, Laura Caso demuestra claramente que la principal estrategia de resistencia de los mayas fue siempre la huida a la selva. Se alejaban así de los centros de dominio español, de los pueblos de encomienda, para residir en las milpas periféricas o en los pueblos de huidos que surgían en las fronteras más remotas de la provincia o, a veces, en los señoríos independientes de la vasta floresta del Petén, entre los cuales el más importante era el de los itzaes. De esta manera hacían de la inmensa selva un aliado clave en su lucha contra la colonización.

Caminos en la selva... muestra con detalle la manera en que los hilos invisibles del parentesco, el comercio y la migración atravesaban la vasta floresta tropical y unían a los pueblos dominados con los pueblos libres, a los indios colonizados con los que todavía eran señores, a Yucatán con el Petén.
Estos vínculos fomentaban la migración de los indios de la región sometida a los españoles hacia los territorios libres y, a la vez, servían para que los itzaes y otros indios no conquistados tuvieran acceso a las mercancías españolas que se les habían hecho indispensables.

Por ello se puede plantear, a partir de la reconstrucción que hace Caso de estos caminos en la selva, que la provincia española de Yucatán y los señoríos mayas independientes llegaron a

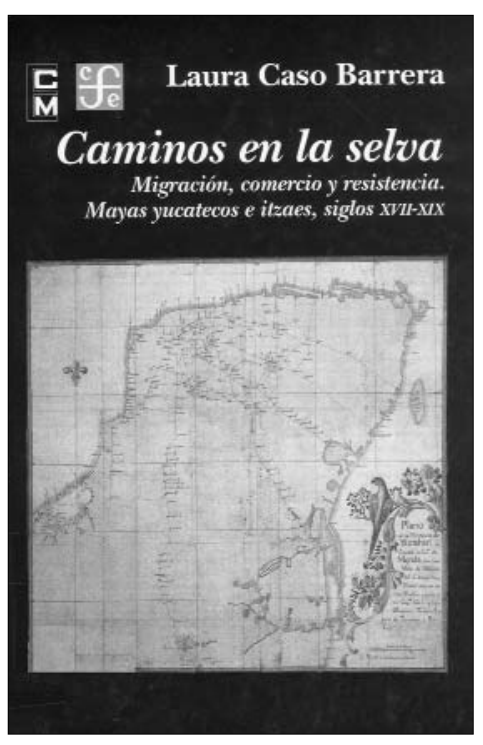

formar un sistema relativamente unificado, aun en contra de su voluntad y más allá de su confrontación irreductible y constante. Por un lado, la constante huida de indios a la selva, a pesar de que debilitaba la base tributaria de la Colonia, quizá sirviera para aliviar la presión sobre el sistema de explotación y se convirtiera en una válvula de escape que prevenía rebeliones abiertas contra el yugo colonial. Por otra parte, los poderosos y orgullosos itzaes, practicantes convencidos y pertinaces de la religión prehispánica, con su complemento de sacrificios humanos, y celosos custodios de su libertad y de la de los otros pueblos de la selva, no podían vivir realmente sin el acceso a los bienes españoles. Esta paradójica simbiosis entre enemigos jurados quizá explique por qué los españoles tardaron más de 150 años en someter definitivamente a los itzaes en 1697 , y por qué los señoríos independientes no parecen haber intentado terminar con la dominación colonial en toda la península.

La importancia de este sistema simbiótico se manifiesta en el hecho de que el colapso del señorío independiente de los itzaes desarticuló las redes migratorias y comerciales mayas, sumiendo a las comunidades de refugiados de la selva en la pobreza y el aislamiento. Por ello, dejó como principal avenida a la resistencia maya la incorporación a las haciendas, donde pese a una condición servil acentuada, los hombres y mujeres indígenas podían escapar a los trabajos forzosos, los repartimientos y otras formas de explotación que padecían en sus pueblos. Quizá podríamos incluso afirmar que la clausura de la migración, como alternativa de resistencia, fue una de las causas profundas de la gran rebelión maya de mediados del siglo XIX, la mal llamada "guerra de castas" que volvió abrir los caminos de la selva y a establecer un señorío maya independiente en medio de la floresta. 


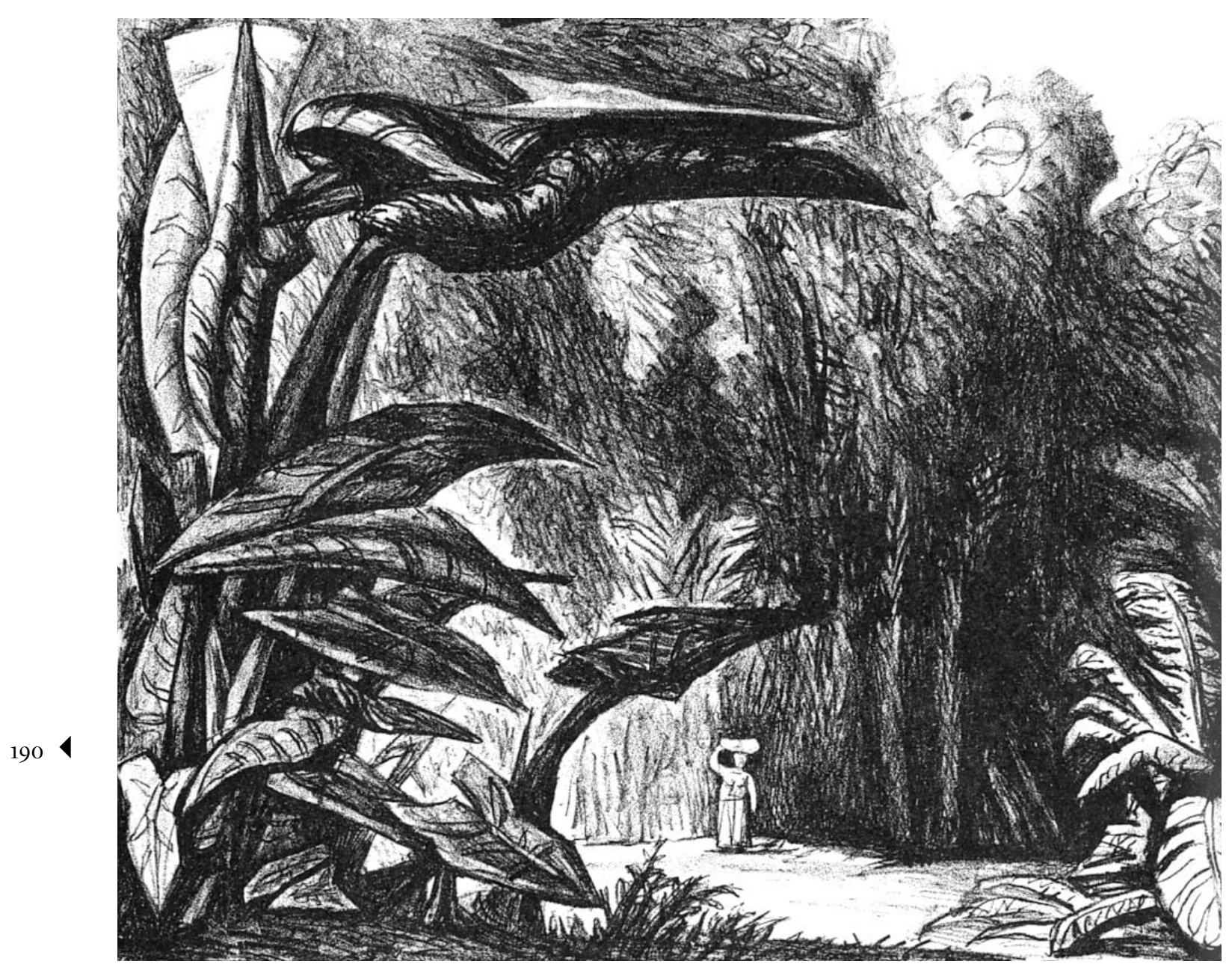

José Chávez Morado, Hojas gigantes, 1950.

Además de presentarnos esta visión global de la situación colonial en Yucatán y el Petén y del papel clave que en ella desempeñaron los itzaes, antes y después de su sometimiento, la riqueza de Caminos en la selva... reside en la manera en que una cuidadosa y paciente labor de criba entre legajos y expedientes permitió a Laura Caso recuperar las figuras individuales de los indígenas que decidieron tomar el camino de la selva, las peripecias de familias que huyeron a la montaña para luego regresar, por la fuerza o por la persuasión, a los poblados colonizados, y después, en ciertos casos, volver a escapar ante las promesas incumplidas y las excesivas cargas de trabajo. Estos casos particulares dan realidad y consistencia a las generalizaciones y nos permiten comprender con una profundidad inusitada los motores y la mecánica de esa venerable tradición maya, la movilidad constante por el mar de la selva, una dinámica que puede explicar tanto el colapso de los grandes reinos clásicos del primer milenio después de Cristo, como la inestabilidad del periodo posclásico, como las peripecias del dominio colonial español, como la exitosísima rebelión y resistencia maya contra el gobierno yucateco y mexicano hasta bien entrado el siglo XX.

Laura Caso señala que la concepción cíclica del tiempo entre los mayas 
y las profecías históricas de la rueda de los katunes, reunidas en los libros del Chilam Balam, fueron otra de las causas y explicaciones de su constante movilidad y su permanente búsqueda de cambios.

Sin embargo, la principal falla de este libro es no profundizar más en los riquísimos textos producidos por los indígenas coloniales para dar una visión más completa de la experiencia maya. Las fuentes que utiliza privilegiadamente Caso, los archivos españoles, nunca dejan (no pueden) de tener una visión externa y ajena sobre la cultura indígena y por lo tanto necesitan de este complemento. Claro que los problemas metodológicos asociados al trabajo con las fuentes coloniales mayas son inmensos, pero más grande hubiera sido la riqueza informativa que se hubiera podido extraer de ellos. Es por esto que, como trabajo de etnohistoria, se extraña en este libro la voz directa de los protagonistas y un análisis más meticuloso sobre sus reacciones culturales a la colonización.

Pero esto no significa que Caminos en la selva... se circunscriba a la visión archivística. La autora presenta una detallada y minuciosa descripción de la riqueza ecológica de la selva, de la diversidad de especies que los mayas explotaban, cultivaban y recolectaban, de la compleja dinámica de su agricultura de roza y quema, de la manera intrincada en que habían logrado armonizar su organización productiva y social con la delicadeza y complejidad del hábitat tropical. Esta visión de ecología humana permite comprender mucho mejor la dinámica social de los mayas y su sorprendente capacidad para prosperar en un medio ambiente que a nosotros, y a los colonizadores españoles, nos parece refractario y pobre. En este aspecto, la autora se pone a la vanguardia de los estudios sobre la agricultura tropical maya y hace eco de los recientes y riquísimos estudios sobre la ecología humana del Amazonas, un campo que ha experimentado un avance deslumbrante en las últimas tres décadas. ${ }^{1}$

En este sentido, el libro de Caso puede abrir todo un nuevo abanico comparativo. La movilidad de los mayas en la selva tropical se puede equiparar a la de pueblos amazónicos como los campas de Perú o los shuar del Ecuador, que también hicieron de la huida a la selva una forma de resistencia eficaz contra el dominio colonial y crearon en su inmensidad incontables sociedades de refugiados. ${ }^{2}$

Pero la analogía es más profunda: al igual que los mayas se aficionaron fatalmente a las herramientas metálicas, y para obtenerlas tuvieron que mantener su contacto con la estructura colonial aun cuando más querían escapar de ella, los amazónicos también han

${ }^{1}$ Emilio F. Morán, La ecología humana de los pueblos del Amazonas, FCE, México, 1993.

2 Véanse, entre otras obras, Fernando Santos, Etnohistoria de la Alta Amazonia, siglos XV$X V I I I$, col. 500 años, núm. 46, Ediciones Abya-Yala, Quito, 1992; Anne-Christinne Taylor, "Génesis de un arcaísmo: la Amazonia y su antropología", en Carmen Bernand (ed.), Descubrimiento, conquista y colonización de América a quinientos años, FCE-CNCA, México, 1994, pp. 91-126; y Michael F. Brown y Eduardo Fernández, War of Shadows. The Struggle for Utopia in the Peruvian Amazon,

University of California Press, Berkeley, 1991. tenido que acercarse a los europeos para obtener hachas de acero para tumbar su selva. Quizá por esta razón hay pueblos, como los wakuenai del río Negro, con tradiciones míticohistóricas que hablan, como la maya, de una alternancia cíclica entre periodos de gran expansión y comercio y periodos en que los caminos se cierran y el mundo se hace pequeño, escaso y pobre, a resultas, al igual que en Yucatán, de la expansión de la dominación colonial. ${ }^{3}$

Por ello se puede plantear que la selva, en ambos casos, ha sido un factor de gran importancia para la dinámica de la colonización española y de la resistencia indígena; y que entender las posibilidades y limitaciones de este medio ambiente, y sobre todo la manera en que los hombres han aprendido a aprovecharlas, es indispensable para comprender la historia de los seres humanos que lo habitan, indígenas y colonizadores.

Es así como el trabajo minucioso y profundo de Laura Caso sobre un periodo específico de la historia maya nos abre avenidas de reflexión y estudio para entender otras etapas de la milenaria tradición de ese pueblo y enriquece también nuestra visión general y comparativa de la interacción entre los colonizadores europeos y las sociedades indígenas en nuestro continente.

${ }^{3}$ Robin M. Wright y Jonathan D. Hill, "History, Ritual and Myth: Nineteenth Century Milleniarian Movements in the North Western Amazon", Ethnohistory, vol. 33, núm. 1, 1986, pp. 31-54. 